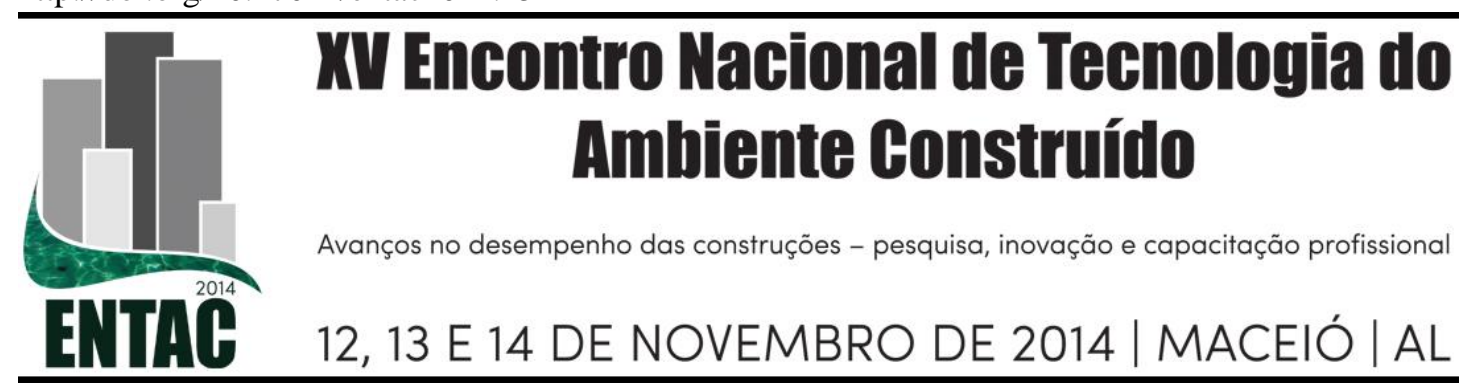

\title{
AVALIAÇÃO DA QUALIDADE ESPACIAL DE EDIFÍCIOS DE APARTAMENTOS EM CIDADES MÉDIAS
}

\author{
VILLA, Simone Barbosa (1); SARAMAGO, Rita de Cássia Pereira (2); \\ ALEXANDRE, Laiza Cunha (3); PIRES, Raisa Gonçalves (4)
}

(1) Universidade Federal de Uberlândia, e-mail: simonevilla@yahoo.com (2) Universidade Federal de Uberlândia, e-mail: saramagorita @gmail.com (3) Universidade Federal de Uberlândia,

laizadacunha@hotmail.com (4) Universidade Federal de Uberlândia, raisagoncalvesp@gmail.com

\begin{abstract}
RESUMO
Este artigo pretende apresentar uma parte da pesquisa, intitulada HABITAR VERTICAL - Avaliação da qualidade espacial e ambiental de edifícios de apartamentos, destacando os resultados referentes às pesquisas e análises do objeto de estudo que enfocam as questões relativas à funcionalidade dos espaços coletivos e privativos - identificando maneiras de morar, necessidades, ações e desejos dos usuários, assim como seu comportamento no espaço doméstico. Tal análise se fundamenta por meio dos seguintes procedimentos metodológicos: (i) Fundamentação teórica do trabalho, através de pesquisa bibliográfica e documental; (ii) Identificação das principais tipologias de edifícios de apartamentos ofertadas pelo mercado imobiliário nas cidades estudadas (Uberlândia - MG e Ribeirão Preto - SP), mediante a elaboração de tabelas e fichas de análise, que destacam características e aspectos funcionais dos empreendimentos; e (iii) Revisão e ampliação do método de APO inicialmente desenvolvido em outras pesquisas para sua aplicação nos estudos de caso selecionados. Os resultados preliminares deste trabalho, que salientam a baixa qualidade espacial dos edifícios investigados, constituem bancos de dados sobre as questões relativas do morar em edifícios de apartamentos, fornecendo subsídios para o desenvolvimento de projetos futuros mais adequados às reais necessidades de seus usuários.
\end{abstract}

Palavras-chave: Qualidade espacial, Avaliação pós-ocupação, Funcionalidade, Edifício de apartamento.

\begin{abstract}
This article aims to present a part of the research entitled VERTICAL HOUSING: Evaluation of spatial and environmental quality of apartment buildings, highlighting the results regarding the analysis of the object of study that focuses on issues relating to the functionality of collective and private spaces identifying ways of live, needs, desires and actions of users, as well as their behavior in domestic spaces. Such analysis is based on the following methods: (i) Theoretical basis of the work, through literature review and study of documents; (ii) Identification of the main typologies of apartment buildings offered by the housing market in the cities studied (Uberlândia - MG and Ribeirão Preto - SP), through tables and schemes of analysis, which highlight functional aspects of residential developments; and (iii) Revision and expansion of the POE method initially developed in other researches for its application in selected case studies. Preliminary results of this study, which focus on the low spatial quality of the investigated buildings, consist of databases on the aspects regarding the living in apartment buildings that could support design of new buildings more suited to the real needs of their users.
\end{abstract}

Keywords: Spatial quality, Post-occupancy Evaluation, Functionality, Apartment Building.

\section{INTRODUÇÃ̃O}

A produção de habitação coletiva vertical, notadamente voltada à ascendente classe média da sociedade, vem passando por um crescimento significativo, o qual, em geral, 
demonstra pouca preocupação com a qualidade das unidades e dos empreendimentos ofertados. Nesse contexto, este artigo pretende apresentar uma parte da pesquisa em desenvolvimento, intitulada HABITAR VERTICAL - Avaliação da qualidade espacial e ambiental de edifícios de apartamentos, que se propõe a realizar um diagnóstico da qualidade espacial e ambiental de edifícios de apartamentos - destinados à classe média e lançados pelo mercado imobiliário em cidades de médio porte brasileiras (Uberlândia - MG e Ribeirão Preto - SP). Entretanto, o presente trabalho tem como objetivo específico analisar a funcionalidade dos espaços coletivos e privativos desses empreendimentos - identificando maneiras de morar, necessidades, ações e desejos dos usuários, assim como seu comportamento no espaço doméstico.

Para tanto, a presente comunicação, de cunho exploratório e descritivo, foi estruturada da seguinte forma: (i) Fundamentação teórica do trabalho; (ii) Indicação dos procedimentos metodológicos utilizados na pesquisa; e (iii) Apresentação de seus resultados preliminares - presentes tanto nas tabelas e fichas de análise produzidas, quanto na revisão do método de avaliação pós-ocupação (APO) que está sendo aplicado nos estudos de caso selecionados. Assim, a próxima etapa da pesquisa, ainda em desenvolvimento, se fundamenta, principalmente, por meio da aplicação de APO em relação aos aspectos espaciais e comportamentais dos edifícios.

\section{CONSOLIDAÇÃO DOS EDIFÍCIOS DE APARTAMENTOS NO BRASIL}

$\mathrm{O}$ surgimento da modalidade apartamento no Brasil remonta à primeira década do século $\mathrm{XX}$, quando as principais cidades, notadamente as capitais e de maior porte, passaram por importantes remodelações urbanísticas, conferindo à habitação convencional térrea, novas possibilidades formais e programáticas - como é o caso dos edifícios múltiplo-uso que mesclavam habitações e escritórios (VILLA, 2008). Desde então, o percentual de edifícios de apartamentos só aumentou na grande maioria das cidades brasileiras, consolidando-se como uma alternativa aos seus problemas urbanísticos e fundiários. Também tem se consolidado como uma maneira de morar particular, representando aspectos objetivos e subjetivos aos cidadãos urbanos frente à segurança, praticidade, localização e status social, entre outros aspectos.

Nas cidades de médio porte - como, por exemplo, Uberlândia (MG) e Ribeirão Preto (SP) -, o edifício de apartamento se tornou, durante a passagem do século XX para o XXI, uma modalidade habitacional crescente e viável para diversas classes sociais. A partir de meados dos anos 2000, esses mercados imobiliários iniciaram um processo de atratividade de empresas de maior porte, oriundas de outras regiões brasileiras. Além disso, devido a políticas governamentais, houve um significativo aumento do acesso ao crédito nos últimos anos, impulsionando a demanda por diferentes tipologias de unidades habitacionais (CORDEIRO FILHO, 2008).

Contudo, este crescimento da produção de edifícios de apartamentos vem sendo frequentemente marcado pela adoção de aspectos padronizados em soluções projetuais diversas - o que demonstra, em geral, pouca preocupação com as reais necessidades do usuário final, cujos modos de vida e formatos familiares estão em constante alteração. Uma análise dos projetos de apartamentos edificados no período pós-2000 deixa evidente o tratamento recebido pelos mesmos, traduzido por uma postura que valoriza substancialmente seus aspectos estéticos e que demonstra, em geral, uma preocupação apenas acessória com as reais necessidades do usuário final (Fig. 1). Nesse sentido, pode-se inferir que o setor desenvolveu-se com uma clara hegemonia dos negócios em detrimento do projeto arquitetônico. 
Figura 1 - Padronização de tipologias e soluções espaciais em apartamentos nas cidades médias modelos de plantas apresentadas para comercialização dos empreendimentos em Uberlândia e Ribeirão Preto, respectivamente.
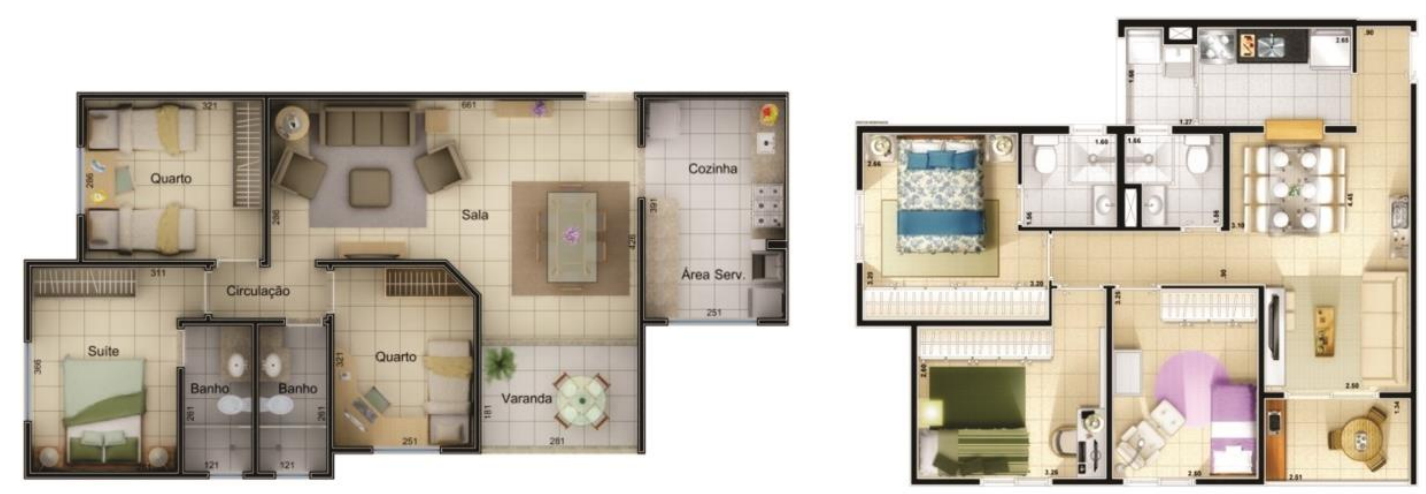

Fonte: http://www.britamix.com.br/novo/empreendimentosDetalhado.php?id=33 e http://www.trisulsa.com.br/apartamentos/ribeirao-preto/lagoinha/vida-plena-ribeirao/. Acesso em: 10/03/2014.

\section{PROCEDIMENTOS METODOLÓGICOS}

Por se tratar de um projeto de pesquisa amplo, que envolve várias etapas de execução, este foi dividido em dois subprojetos: (i) Padrões projetuais em edifícios de apartamentos a partir de 2000 nas cidades estudadas; e (ii) Identificando modos de morar, através da avaliação pós-ocupação funcional e ambiental. Aplicação dos estudos de casos nas cidades estudadas. Até o presente momento, foi concluída a primeira etapa descrita acima, na qual pudemos levantar e analisar as principais tipologias de edifícios de apartamentos ofertadas pelo mercado imobiliário nas cidades estudadas. A segunda etapa foi iniciada com a revisão da metodologia de avaliação pós-ocupação para aplicação em estudos de caso nessas cidades (conforme apresentado no item 4.2).

Desse modo, inicialmente, para cada cidade, foi elaborada uma tabela, a qual levanta os edifícios construídos ou em fase de construção, organizando-os e sistematizando-os em formato digital ${ }^{1}$. A partir dela, foi possível filtrar informações gerais para selecionar os empreendimentos sobre os quais seriam realizadas fichas de análise, que contemplam os detalhes projetuais das tipologias selecionadas, ajudando na catalogação, no arquivamento e na melhor compreensão do projeto. Assim, foram analisados 63 edifícios de apartamentos localizados na cidade de Uberlândia e 106 na cidade de Ribeirão Preto ${ }^{2}$. Nesta fase, utilizaram-se os mesmos critérios de seleção de incorporadoras para ambas as cidades, buscando um nível igualitário para se obter uma possível comparação entre elas, quais sejam: (i) atuarem em território nacional e local; e (ii) atenderem à classe média da sociedade, ofertando apartamentos com áreas úteis entre 40 e $300 \mathrm{~m}^{2}$. O preenchimento da ficha, por sua vez, desenvolveu-se em três partes: (a) Dados gerais; (b) Edifício: forma plástica e imagem, estrutura, inserção urbana, funcionalidade, equipamentos de uso coletivo, adequação legal/ambiental e segurança; e

\footnotetext{
${ }^{1}$ Esta tabela, além de identificar os empreendimentos, coleta informações sobre: fonte, nome, data de publicação, data de projeto, data de conclusão, autor do projeto, proprietário, construtora, localização, área construída/área do terreno implantado, número de edifícios, número de pavimentos, número de unidades, tipos de uso, equipamentos coletivos, acessibilidade, uso dos elevadores, tipos de unidade, áreas úteis, opções de planta, tipos de cômodos e atividades em geral.

${ }^{2}$ Estes foram os empreendimentos lançados nas respectivas cidades no período da pesquisa, sobre os quais pudemos ter acesso a todas as informações necessárias (através de material publicitário, sites, entre outras fontes). Observa-se que, na cidade de Ribeirão Preto, o número de empreendimentos lançados no período foi superior ao de Uberlândia e, por isso, optou-se por manter esta proporção na seleção dos empreendimentos analisados.
} 
(c) Apartamento: quadro de referências e quadro de áreas, análise de espaciosidade (Fig. 3), mapa de ações domesticas cotidianas (Fig. 2) e setorização.

Figura 2 - Elementos gráficos contidos na ficha de análise de um empreendimento na cidade de Ribeirão Preto, mostrando as ações cotidianas propostas para cada tipologia.
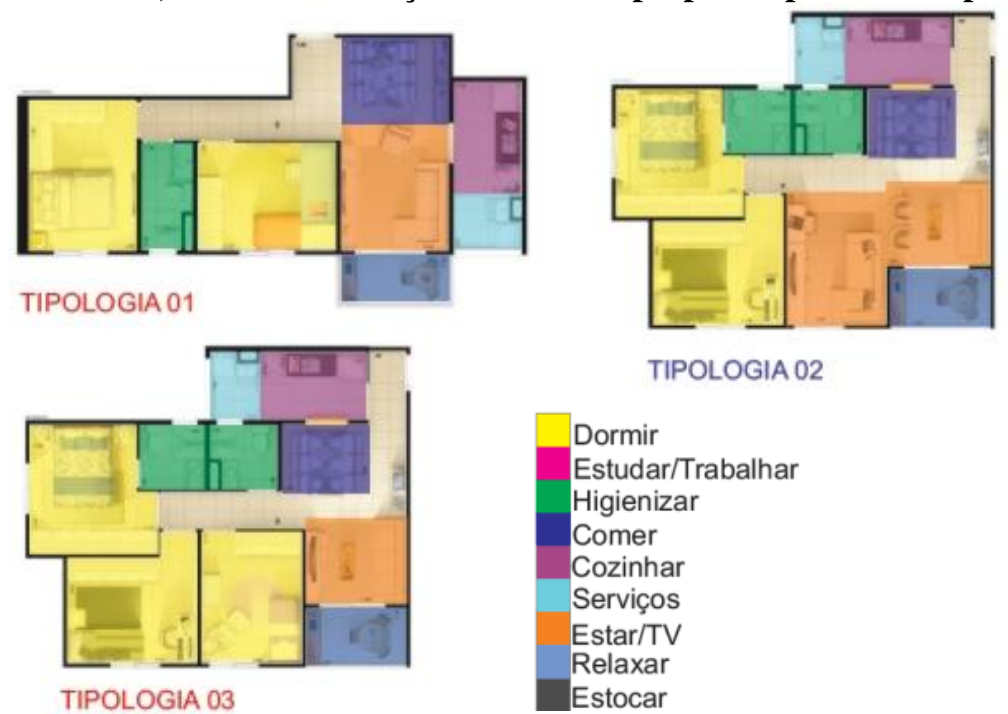

TIPOLOGIA 02

Dormir

Estudar/Trabalhar

Higienizar

Comer

Cozinhar

Serviços

Estar/TV

Relaxar

Estocar

Fonte: Organizado pelas autoras (2013).

Figura 3 - Elementos gráficos contidos na ficha de análise de um empreendimento na cidade de Ribeirão Preto, demostrando a análise de espaciosidade.

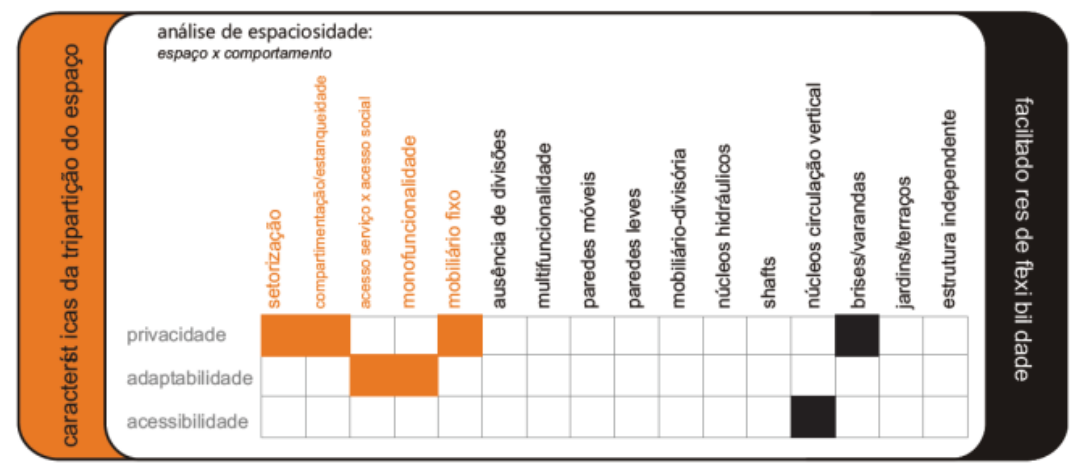

Fonte: Organizado pelas autoras (2013).

Já a segunda etapa desta pesquisa trata da identificação dos modos de morar em edifícios de apartamentos, através da avaliação pós-ocupação (APO) funcional e ambiental. Nesse sentido, testa e valida um método de APO do espaço habitacional, desenvolvido em pesquisas anteriores (VILLA, 2008; VILLA, 2010), que se aprofunda nas questões relativas à funcionalidade. Amplia ainda o método de APO inicialmente desenvolvido para englobar questões relativas à sustentabilidade dos edifícios analisados (segunda linha de investigação da pesquisa), verificando a eficiência das estratégias de sustentabilidade adotadas junto aos usuários, bem como seu nível de consciência ambiental ${ }^{3}$.

A avaliação funcional e comportamental utiliza-se de multimétodos de naturezas quantitativas e qualitativas, enfocando os seguintes pontos: (i) as maneiras de apropriação dos espaços privados e semiprivados; (ii) a adequação da proposta projetual às novas solicitações emergentes da sociedade e (iii) os índices de satisfação dos usuários moradores. Esta metodologia de APO foi idealizada também com o objetivo de

\footnotetext{
${ }^{3}$ Resultados sobre esta linha de investigação estão disponíveis na publicação: Qualidade ambiental e sustentabilidade em edifícios de apartamentos de cidades médias, apresentados neste mesmo evento.
} 
dispor a especialistas - profissionais e agentes do mercado imobiliário - ferramentas que pudessem atestar a qualidade espacial de apartamentos, além de avaliar a capacidade do projeto idealizado de atender às demandas dos usuários.

Sendo assim, visou-se à elaboração de um método prático, viável do ponto de vista econômico e baseado em procedimentos e técnicas adequadas à modalidade habitacional. Se, de um lado, entende-se a necessidade da proposição de métodos avaliativos que obtenham informações mais consistentes e amplas - demandando mais tempo de pesquisa -, de outro, depara-se com a necessidade da proposição de métodos economicamente viáveis e eficientes. Isto se verifica tanto do ponto de vista do usuário, que se envolve pouco no processo avaliativo, quanto do ponto de vista dos agentes do mercado imobiliário, que buscam resultados em curtos espaços de tempo e com baixo custo de investimento. Nesse sentido, buscou-se, em parceria com outra pesquisa ${ }^{4}$, o aprimoramento metodológico necessário para cumprir tais objetivos. $\mathrm{O}$ avanço metodológico apresentado diz respeito à utilização de equipamento tablet portátil, contendo um conjunto softwares especialmente desenhados para a APO, aprimorando tanto a coleta, quanto a tabulação de dados.

Quadro 1- Conceitos avaliados no questionário - aspectos relativos à funcionalidade e ao modo de vida dos usuários

\begin{tabular}{|c|c|}
\hline \multicolumn{2}{|c|}{ PRINCIPAIS CONCEITOS A VALIADOS NO QUESTIONÁRIO - FUNCIONALIDADE } \\
\hline ESPAÇO COLETIVO (USO COMUM) & ESPAÇO PRIVATIVO (UNIDADE) \\
\hline Acessibilidade das áreas & Diversidade de tipologias \\
\hline Separação entre acesso social e serviço & Área útil da unidade \\
\hline Conservação do espaço de uso comum & $\begin{array}{l}\text { Satisfação em relação à dimensão, iluminação, } \\
\text { ventilação, acústica, privacidade em cada cômodo }\end{array}$ \\
\hline $\begin{array}{c}\text { Satisfação em relação à dimensão e aparência } \\
\text { de: elevadores; hall principal e guarita }\end{array}$ & Compartimentação proposta pelo projeto \\
\hline \multirow{3}{*}{$\begin{array}{c}\text { Satisfação em relação à quantidade e qualidade } \\
\text { dos espaços de uso comum (academia; piscina; } \\
\text { playground, etc) }\end{array}$} & Adequação ao modo de vida do usuário \\
\hline & Adequação dos mobiliários ao espaço \\
\hline & Representação simbólica da habitação para o usuário \\
\hline \multirow{3}{*}{$\begin{array}{l}\text { Frequência de uso dos espaços de uso comum } \\
\text { (academia; piscina; playground, etc) }\end{array}$} & Reformas realizadas e seus respectivos motivos \\
\hline & $\begin{array}{l}\text { Análise de ações domésticas cotidianas em cada } \\
\text { cômodo }\end{array}$ \\
\hline & Análise da qualidade de ações domésticas cotidianas \\
\hline
\end{tabular}

Fonte: Organizado pelas autoras (2014).

A APO, elaborada com diversos métodos, divide-se em sete etapas: levantamento de Dados; análise Walkthrough; pesquisa de perfis familiares; entrevistas com pessoas chave; questionário; grupo focal e, por fim, entrevista com o arquiteto. Os critérios utilizados para definição dos estudos de caso nas cidades de Ribeirão Preto e Uberlândia foram: (i) empreendimentos destinados às famílias de classe média/alta; (ii) entregues entre 2012 e 2014; (iii) com número mínimo de 30 unidades; (iv) possuindo equipamento de uso coletivo; e (v) área útil de 90 a $120 \mathrm{~m}^{2}$. A avaliação está sendo aplicada em dois edifícios em cada cidade, ao longo do ano de 2014, pelos alunos bolsistas de iniciação científica envolvidos nesta etapa da pesquisa ${ }^{5}$. Os conteúdos abordados na APO também foram definidos a partir de questões identificadas nas análises decorrentes da primeira

4 Pesquisa financiada pela FAPEMIG, que se intitula AVALIAÇÃO PÓS-OCUPAÇÃO EM APARTAMENTOS COM INTERFACES DIGITAIS, desenvolvida pelo mesmo grupo de pesquisa em outra linha de investigação.

5 Como esta etapa da pesquisa está em desenvolvimento, com previsão de término para dezembro de 2014, trataremos neste artigo apenas de uma parte inicial da avaliação, mediante análise dos dados resultantes de uma aplicação Piloto do método revisado em Uberlândia (ver item 4.2). 
etapa desta pesquisa, avaliando-se, portanto, aspectos gerais do edifício, os equipamentos de uso comum e a unidade habitacional (Quadro 1).

\section{RESULTADOS PRELIMINARES}

\subsection{Padrões projetuais em edifícios de apartamentos}

A partir das análises realizadas através da elaboração das fichas, foram identificadas as principais tipologias de edifícios de apartamentos ofertadas pelo mercado imobiliário nas cidades estudadas. Os resultados destas análises foram compatibilizados com a fundamentação bibliográfica e estruturados em três escalas de leitura: (i) Inserção urbana; (ii) Equipamentos de uso coletivo; e (iii) Unidades habitacionais.

\section{Inserção Urbana}

As cidades médias estudadas (assim como grande parte do país), após os anos 2000, sofreram transformações urbanísticas, arquitetônicas, econômicas, culturais e sociais que potencializaram a verticalização das residências. Segundo Polidori e Krafta (2003), a cidade passa então a ser um campo de oportunidades de obtenção de renda, em que a configuração do espaço e a distribuição de atributos urbanos e ambientais provocam crescimento em lugares com maior potencial de desenvolvimento. Analisando a produção de edifícios de apartamentos em Ribeirão Preto e Uberlândia, observa-se que sua implantação segue a mesma lógica, a partir da identificação de elementos que possam trazer maior lucratividade possível à incorporadora - que procura uma desejável relação entre o preço da terra e o custo da construção. Com o aquecimento do mercado imobiliário, o preço do solo aumenta e o rendimento financeiro diminui. Assim, novos locais são escolhidos na cidade, geralmente periféricos, para a inserção dos empreendimentos, explorando ao máximo o terreno. Como consequência, em Uberlândia, a inserção dos conjuntos acontece de forma dispersa, não se concentrando em um local específico, enquanto os gabaritos variam entre 2 e 12 pavimentos, com predomínio das tipologias de 2 e 3 dormitórios - diferentemente de Ribeirão Preto, em que existe uma grande concentração no setor sul da cidade, atingindo desde 2 a 21 pavimentos, com uma variação muito maior de tipologias (Fig. 4).

Figura 4 - Mapas de localização dos empreendimentos analisados nas cidades estudadas com indicação das tipologias presentes nos edifícios
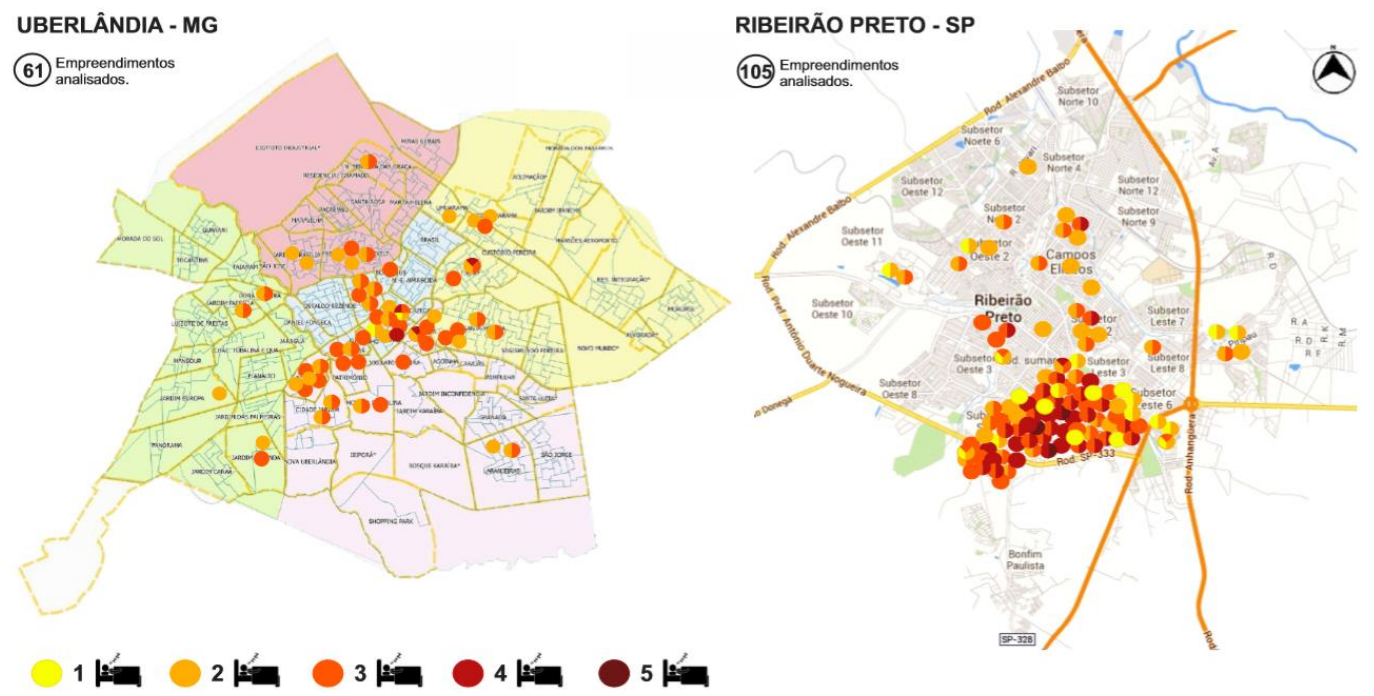

Fonte: Organizado pelas autoras (2013). 
Sobre o desenho de implantação destes edifícios, a grande maioria apresenta soluções fechadas, frequentemente muradas, em relação ao espaço público. Representam verdadeiras "ilhas" na cidade, independente do contexto no qual se localizam, negligenciando, muitas vezes, aspectos topográficos, de insolação e ventilação locais. Também apresentam soluções padronizadas de implantação no que se refere à implantação dos blocos, soluções de estacionamento, ocupação dos espaços verdes residuais e relação com o entorno, entre outros aspectos.

\section{Equipamentos de uso coletivo}

Historicamente a produção de edifícios de apartamentos esteve ligada à produção de espaços coletivos, sobretudo a partir dos anos 1970, quando os empreendimentos, principalmente de alto luxo, iniciam um processo de valorização da esfera coletiva dos edifícios, caracterizado pelo surgimento de equipamentos de uso coletivo (MACEDO, 1991 apud TRAMONTANO, 1998). Além da presença de uma variada gama de equipamentos coletivos, tornava-se importante explicitar de que forma os mesmos poderiam influir no status social dos moradores, enfatizando-se os itens essenciais para se viver bem na maioria dos lançamentos de apartamentos nas grandes cidades. Através dos atributos anunciados, expectativas em torno do morar foram criadas e recriadas, o que, por sua vez, alimentou a formulação de programas arquitetônicos, bem como constituiu certa cultura do morar (LOUREIRO e AMORIM, 2005). Esta valorização das esferas coletivas pode ser notada em parcela expressiva dos edifícios de apartamentos lançados no Brasil, em medidas diferentes, dependendo da classe social a que se destina.

Nas cidades estudadas, frequentemente são previstas áreas de uso coletivo para os empreendimentos verticais. Essas áreas, em geral, são relacionadas ao lazer, esporte e bem-estar de seus potenciais moradores. Na cidade de Uberlândia, os equipamentos ofertados se restringem, na maioria dos casos, aos básicos: salão de festas, playground e área verdes de convívio. Cenário este que tem se alterado, principalmente nos últimos anos, com o lançamento de condomínios verticais e horizontais. Neles, a listagem de equipamentos é ampliada com a presença de academia, quadra poliesportiva, brinquedoteca, piscina e churrasqueira, por exemplo. Já em Ribeirão Preto, mesmo nos casos investigados, a listagem de equipamentos é bastante ampliada, destacando-se: quadra de squash, salão de jogos, SPA, salão de beleza. Predominantemente são implantados em terrenos maiores, procurando adensar mais o edifício principal para deixar livres áreas destinadas à provisão desses equipamentos.

\section{Unidades habitacionais}

Mesmo que atualmente as habitações contemplem grupos familiares com perfis e modos de vida cada vez mais diversos, o desenho dos apartamentos continua baseado em modelos tripartidos de morar, caracterizados por espaços compartimentados, estanques e monofuncionais. Sobre a relação dimensional homem/ambiente construído habitável, vários autores ponderaram sobre possíveis indicadores mínimos (ROMÈRO e ORNSTEIN, 2003; LEITE, 2006; PALERMO, 2009). Nas análises, verificou-se que, na grande maioria dos apartamentos avaliados, as áreas dos compartimentos, notadamente os dormitórios, áreas de serviços e cozinhas, são inferiores aos mínimos exigidos pelos autores citados acima. Em Uberlândia, a exiguidade de áreas se demostrou mais evidente do que em Ribeirão Preto - isso porque, de forma geral, os edifícios analisados na última cidade contemplavam um padrão social mais elevado (Fig. 5). A exiguidade de áreas não é um fator preponderante para a baixa qualidade dos projetos, porque poderia estar justificada pela redução do tamanho da família brasileira. No entanto, o produto imobiliário ofertado não parece demonstrar essa relação. Empreendimentos 
residenciais deveriam revisar então não somente a área útil dos apartamentos, mas sua organização espacial, levando em consideração as alterações sociais e culturais locais.

Figura 5 - Predominância da tipologia de 2 e 3 dormitórios nas cidades estudadas e suas principais características. As áreas úteis apresentadas representam a média geral dos empreendimentos analisados na pesquisa.

UBERLÂNDIA - MG
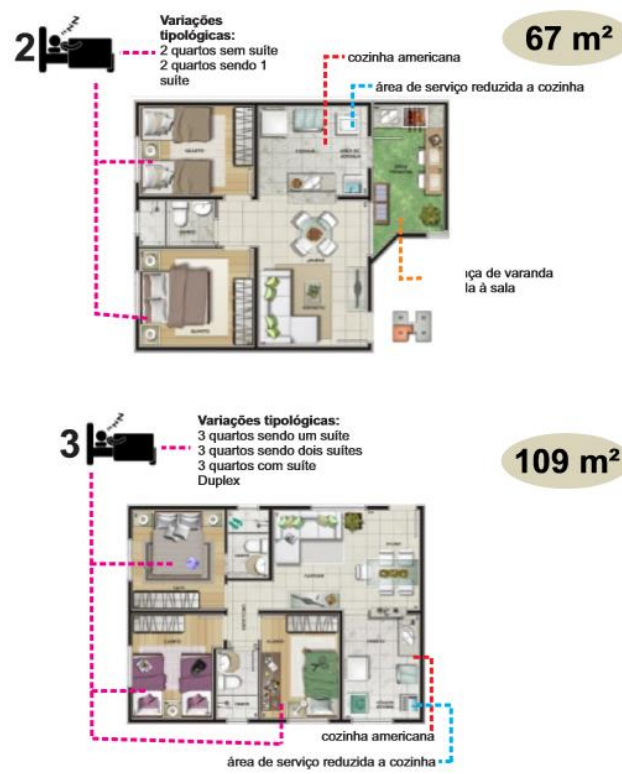

$109 \mathrm{~m}^{2}$
RIBEIRÃO PRETO - SP
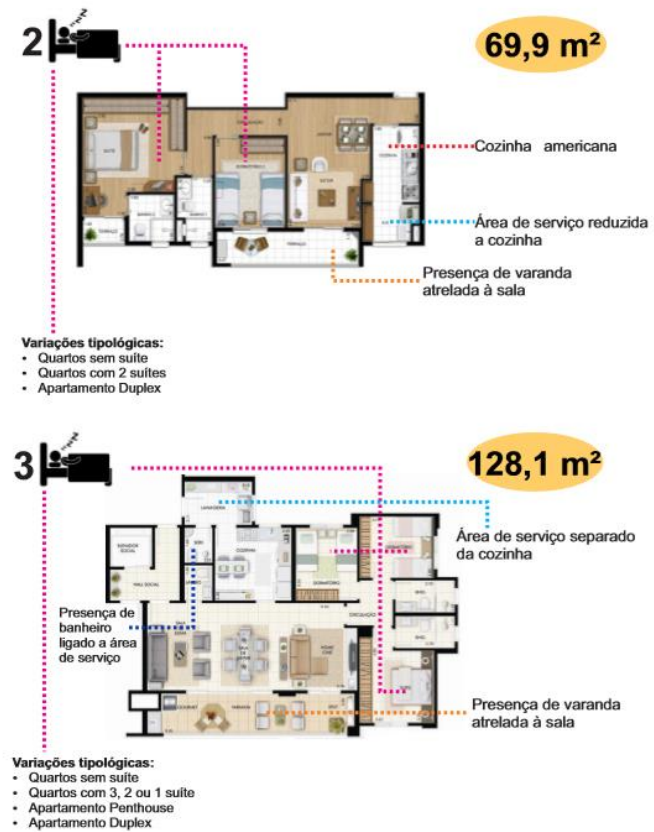

Fonte: Organizado pelas autoras (2014).

Figura 6 - Apartamentos de 2 dormitórios. Acima: usos domésticos inicialmente previstos em projeto através do leioute. Abaixo: sobreposição de usos no espaço.
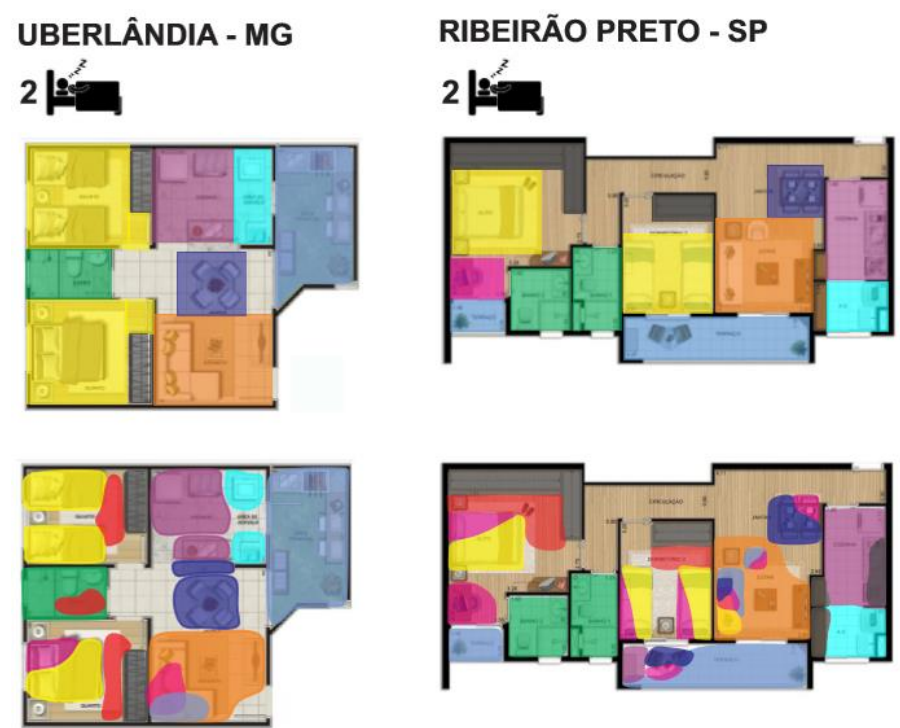

ACÕES:

DORMIR

DORMIR
ESTUDARTIRABALHAR

HIGIENIZAR

COMER

COZINHAR

LAVARJPASSAR ROUPA

ESTARIASSISTIR TV

RELAXAR

ESTOCAR

VESTIR

Fonte: Organizado pelas autoras (2014).

Outra questão observada nas análises dos apartamentos se refere à incongruência entre os usos cotidianos propostos no projeto (leiaute idealizado pela incorporadora do empreendimento) e os frequentemente realizados pelos moradores. Nesse sentido, foram verificadas inúmeras sobreposições de usos nos compartimentos habitacionais. Ações cotidianas domésticas, tradicionalmente pré-estabelecidas em projeto para serem 
executadas em determinados cômodos, foram identificadas de forma dispersa e não convencional nos espaços analisados (Fig. 6). Afinal, a proposta das incorporadoras comumente não supre o mínimo exigido para exercer atividades simples em cada cômodo. Assim, ações como trabalhar, estudar e comer cada vez mais são realizadas em áreas diferentes das previstas, principalmente pela falta de espaço nos ambientes. Esses conflitos de ações aparecem com mais frequência em empreendimentos destinados às classes mais baixas, em que as áreas úteis dos apartamentos são menores.

\subsection{Identificando modos de morar, através da Avaliação Pós-Ocupação}

A segunda etapa desta pesquisa, conforme exposto, trata da identificação dos modos de morar em edifícios de apartamentos através da APO funcional e ambiental. Até a finalização deste artigo, foi iniciada com: (i) revisão da metodologia da APO para aplicação em estudos de caso nas cidades estudadas e (ii) aplicação de um Piloto na cidade de Uberlândia ${ }^{6}$. A aplicação dos instrumentos neste Piloto e uma leitura preliminar dos resultados puderam já fomentar algumas reflexões apontadas a seguir? ${ }^{7}$.

Os principais resultados preliminares obtidos nesta avaliação demonstraram a ineficiência e a inadequação dos projetos propostos aos novos modos de vida da sociedade contemporânea. Todos os métodos aqui demonstrados e aplicados em diferentes escalas e conteúdos puderam identificar tais inadequações. Isso porque, de um lado, os projetos idealizados apresentam modelos de unidades estanques, compartimentadas e tripartidas que se repetem em pavimentos; por outro lado, a pesquisa indicou uma variedade significativa de grupos domésticos habitando tais edifícios.

Os indicadores de insatisfação demonstraram predominância nos aspectos que estão ligados à adequação dos projetos no que se refere às dimensões dos ambientes, à adequação dos mobiliários, à relação de privacidade dos moradores e à compartimentação proposta, entre outros aspectos (como a segurança em relação ao ambiente externo e o isolamento acústico entre as unidades). Os métodos qualitativos, principalmente o Grupo Focal, se mostraram mais eficientes na identificação de desejos em relação ao espaço habitável dos moradores. Nesses métodos, a inadequação se apresentou de forma mais explícita, exatamente porque foram discutidas outras possibilidades de usos dos espaços.

Identificaram-se ainda a sobreposição de atividades na grande maioria dos ambientes das unidades e a consequente falta de espaços e mobiliários eficientes para tais sobreposições. Os hábitos e costumes das famílias são atendidos de maneira mínima pela tripartição e compartimentação, já que os usuários apresentam necessidades e desejos diferentes dos propostos pelos projetos. Sobre os espaços de uso coletivo, as avaliações identificaram que os equipamentos são valorizados no momento da compra, mas cada vez estão sendo menos utilizados no cotidiano pelos moradores.

\section{CONSIDERAÇÕES FINAIS}

Os resultados preliminares desta pesquisa demonstram a necessidade e urgência da ampliação dos padrões de qualidade espacial dos edifícios de apartamentos, no sentido de atenderem amplamente às necessidades de seus usuários. Este estado da arte permite

\footnotetext{
${ }^{6}$ Trata-se de um empreendimento analisado na primeira etapa da pesquisa, localizado na cidade de Uberlândia, que apresenta todos os requisitos definidos na metodologia (item 3) para sua escolha: possui duas torres de edifícios com um total de 112 apartamentos de 3 e 4 dormitórios, com área útil de $97 \mathrm{~m}^{2}$, contendo equipamentos de uso coletivo (quadra, salão de festas, quiosque, piscina e academia).

${ }^{7}$ Não houve tempo hábil para a completa tabulação e análise dos resultados obtidos nesta etapa da pesquisa, as quais se pretende viabilizar futuramente em outra publicação.
} 
aventar a hipótese de que a qualidade arquitetônica dos empreendimentos habitacionais verticais seja baixa, face à importância que o tema ocupa no cotidiano das pessoas e das cidades. Conforme exposto, cada vez mais o mercado imobiliário tem recorrido à habitação verticalizada coletiva como resposta à demanda habitacional, sobretudo para a classe média. Questões como a segurança, praticidade, localização, estimulam populações urbanas a morar em apartamentos. Entretanto, a estandardização, a minimização de áreas úteis das unidades habitacionais, a replicação de soluções frente à diversidade de contextos, dentre outros aspectos, estão contribuindo para baixos níveis de satisfação dos moradores frente ao que se coloca - como foi comprovado ao longo da análise das fichas produzidas e dos dados iniciais obtidos a partir da aplicação do método revisado de APO em um estudo de caso Piloto. Sendo assim, acredita-se que os resultados levantados pela pesquisa podem ser usados como bancos de dados sobre as questões relativas do morar em edifícios de apartamentos, fornecendo subsídios para o desenvolvimento de projetos futuros mais adequados às reais necessidades de seus usuários.

\section{AGRADECIMENTOS}

Agradecemos aos órgãos financiadores da pesquisa: CNPq, FAPEMIG e PROGRAD/UFU.

\section{REFERÊNCIAS}

CORDEIRO FILHO, A. Empreendedorismo no mercado imobiliário habitacional. São Paulo: Atlas, 2008.

LEITE, L. C. R. Avaliação de Projetos Habitacional: Determinando a Funcionalidade da Moradia Social. São Paulo: Ensino Profissional, 2006.

LOUREIRO, C.; AMORIM, L. Dize-me teu nome, tua altura e onde moras e te direi quem és: estratégias de marketing e a criação da casa ideal - parte 1 e parte 2. ARQUITEXTOS: Periódico Mensal de Textos de Arquitetura, Campinas, $\mathrm{n}^{\circ}$ 281, fevereiro de 2005.

PALERMO, C. A Sustentabilidade Social do Habitar. Florianópolis: Carolina Palermo, 2009.

PEDRO, J. B. Definição e avaliação da qualidade arquitetônica habitacional. São Paulo, SP. 2002. p. 95-111. SEMINÁRIO INTERNACIONAL NUTAU, 2002. Artigo Técnico.

POLIDORI, M. C. e KRAFTA, R. Crescimento urbano - Fragmentação e sustentabilidade. Anais X Encontro Nacional da ANPUR. Belo Horizonte: ANPUR, 2003.

ROMÉRO, M. de A.; ORNSTEIN, S. W. Avaliação Pós-Ocupação. Métodos e técnicas aplicados à habitação social. Porto Alegre: ANTAC - Associação Nacional de Tecnologia do Ambiente Construído, COLEÇÃO HABITARE. 2003.

TRAMONTANO, M. Novos modos de vida, novos espaços de morar - Paris, São Paulo, Tokyo: uma reflexão sobre a habitação contemporânea. 1998. Tese (Doutorado) - Universidade de São Paulo, São Paulo, 1998.

VILLA, S. B. Morar em Apartamentos: a produção dos espaços privados e semi-privados nos apartamentos ofertados pelo mercado imobiliário no século XXI - São Paulo e Ribeirão Preto. Critérios para Avaliação Pós-Ocupação. 2008. Tese (Doutorado) Universidade de São Paulo, São Paulo, 2008.

VILLA, S. B. A APO como elemento norteador de práticas de projeto de HIS: O caso do projeto [MORA]. In: CONGRESSO INTERNACIONAL HABITAÇÃO NO ESPAÇO LUSÓFONO, Anais..., Lisboa, Portugal, 22-24 Setembro 2010.

VILLA, S. B.; ORNSTEIN, S. W. (Org.) Qualidade ambiental na habitação: avaliação pósocupação. São Paulo: Oficina de Textos, 2013. 